\title{
The implementation of innovative initiatives to enhance distance learning for Australian undergraduate nursing and midwifery students
}

\author{
Jacqueline O'Flaherty ${ }^{* 1}$, Hayley Timms ${ }^{2}$ \\ ${ }^{1}$ School of Pharmacy and Medical Science, University of South Australia, Adelaide, Australia \\ ${ }^{2}$ Division of Health Sciences, University of South Australia, Adelaide, Australia
}

Received: September 25, 2014

DOI: $10.5430 /$ jnep.v5n1p107
Accepted: October 23, $2014 \quad$ Online Published: November 5, 2014

URL: http://dx.doi.org/10.5430/jnep.v5n1p107

\begin{abstract}
Providing distance education students with different modes of study and interactive online learning resources has become an increasingly important part of nursing and midwifery higher education. In 2006, the number of students enrolled 'externally' in a compulsory foundation course (anatomy and physiology) comprised 38\% of the total cohort of students (this percentage is three times the Australian HE standard for students studying externally). In response to student feedback and ongoing critical reflection a number of factors were identified that led to student dissatisfaction as well as a lower retention rate compared to the on-campus cohort. External students also reported anxiety about studying in an online environment, returning to study and study workload. In order to overcome these anxieties, provide support and assist with student retention and satisfaction, a number of innovative learning initiatives using emerging educational tools and technologies were developed and implemented. This paper discusses the results of both the early and more recent initiatives introduced into a course that was initially designed for only face-to-face students but has since been redesigned to include and support the unique needs of the external learner.
\end{abstract}

Key Words: Online learning, Distance learning, Blended learning, Student engagement, Peer support, Virtual classroom, Assessment, Synchronous learning

\section{Introduction}

Supporting student engagement is challenging at the best of times but it is becoming increasingly difficult to engage distance education (external) students with course materials even with the proliferation of online learning technology. In 2010 just under one million (81\%) higher education students in Australia were studying internally (on-campus), $12 \%$ were external (off-campus) and the remaining $7 \%$ were multi-modal (distance or online delivery). ${ }^{[1]}$ With the increase of technology via computers, laptops, tablets and mobile devices it is necessary for higher education to keep pace with new ways of delivering teaching across multiple media and for multiple offerings. Over the last four years, our University has implemented a new Learning Management System (LMS) that incorporates websites, lecture podcasting, online assessment submission, online assessment marking, online plagiarism, online evaluation, ePortfolio and virtual classroom tools. Whilst the new initiatives took into account the existing online tools available, the main aim was to modify these and introduce new technologies to increase external student engagement and promote an online sense of community.

\footnotetext{
* Correspondence: Jacqueline O’Flaherty; Email: jackie.oflaherty@unisa.edu.au; Address: School of Pharmacy and Medical Science, University of South Australia, Adelaide, Australia.
} 


\section{Literature review}

Even though we have access to numerous online teaching tools we know that teaching is not all about the technology. The literature tells us that one of the primary components of effective online teaching is student engagement and that engagement is critical for learning. ${ }^{[2,3]}$ This is also supported by Bryson and Hand ${ }^{[4]}$ who established that students were more likely to engage if they were supported by educators who established inviting learning environments, demanded high results, challenged them and were available for discussion. Hockings et al. ${ }^{[5]}$ suggests that students who are most deeply engaged will reflect, question, conjecture, evaluate and make connection between ideas. In contrast students who are disengaged appear to take a surface approach to learning by copying out notes, focusing on fragmented facts and jumping to conclusions.

Successful online learning puts the needs of the learner first, provides quality and clarity of learning materials and student support. ${ }^{[6]}$ There are many definitions of online learning or e-learning in the literature. Clark and Mayer ${ }^{[7]} \mathrm{de}-$ scribe e-learning as "...instruction delivered on a digital device such as a computer or mobile device that is intended to support learning. Garrison ${ }^{[8]}$ formally defines e-learning as “... electronically mediated asynchronous and synchronous communication for the purpose of constructing and confirming knowledge". Horton ${ }^{[9]}$ defines e-learning as, “. . . the use of information and computer technologies to create learning experiences". Our definition of e-learning is a combination of all three as we are using technology to deliver synchronous learning to promote successful online communities and inquiry based learning.

Part of the success of the initiatives was due to the implementation of a continuous improvement culture by staff of the learning and teaching process. ${ }^{[10]}$ By reviewing, then introducing new online initiatives, the foundation course provided students with a platform where learning occurs but also promotes participation in their own online community, leading to higher student satisfaction with the course. ${ }^{[11]} \mathrm{We}$ found that a positive learning environment significantly affects students' learning satisfaction ${ }^{[12]}$ and that communication and responsiveness were also key elements linked to student satisfaction. ${ }^{[13]}$

The literature shows that there are links between student satisfaction and student retention. Studies show that the failed retention rate of online courses to be 10 to $20 \%$ higher than traditional classroom environments. ${ }^{[14,15]}$ If 'atrisk' students withdraw from their studies, this is a potential loss to the university and society, especially considering there is both a national and global shortage of nurses. The Australian Health Workforce 2025 study found that there will be a highly-significant shortage of nurses $(109,000)$ by 2025. ${ }^{[16]}$ It can also be a devastating loss to the students themselves. Gaskell ${ }^{[17]}$ explains that both student satisfac- tion and retention have similar themes: monitoring student progress in order to provide support, timely feedback on assessments and contact with teaching staff. The literature shows that staff play an important role in the student experience and student-staff interaction is related to retention: the more positive and higher interaction students have with staff, the higher the retention. ${ }^{[18,19]}$

\section{Methods}

\subsection{Data collection}

The data presented in this paper includes information collected from cohorts of external nursing and midwifery students studying a first year Bioscience course over a number of years (2006-2013). A mixed methodology was used to collate the information from four different mechanisms and measure its success:

(1) Course Evaluation Instrument (CEI) that measured student satisfaction of the course

(2) online questionnaires concerning student engagement with virtual classrooms

(3) improvement/decline of student grades

(4) student retention rates

\subsection{Ethics}

Ethics approval was granted by the university Human Ethics Committee and written permission was gained from the Provost for the collection and use of the data. The course evaluation instrument and online questionnaires were anonymous and voluntary.

\section{Initiatives (2007-2011)}

At UniSA the external Bioscience students have tended to be supported in their learning through asynchronous activities such as electronic documents, lecture recordings, and discussion forums initially designed to support on campus students. External student feedback suggested that these learning activities were not providing effective support for their learning. Therefore, the following initiatives were developed to assist external student engagement with some being extended to on-campus cohorts as well.

\subsection{Podcasts}

In 2007, the bioscience courses were 'early adopters' of audio podcasts of lectures to support external students. At that time few other universities were podcasting in education. ${ }^{[20]}$ To determine the actual impact of these technologies and applications on student learning, a survey of over 1600 students was conducted in 2009 in an effort to:

(1) understand better how students use podcasts in their studies 
(2) to advise students and staff on the usefulness of podcasts, and

(3) to develop best practice guidelines for the use of podcasting of teaching materials across the entire Health Division

One challenge inherent to external teaching and learning has been that students usually lack formal opportunities to engage in assignment feedback. A survey of bioscience students identified a lack of consistent feedback as a contributing factor to their dissatisfaction and anxiety with the online courses. In response to the survey several initiatives were introduced: the podcast lectures of key concepts (6-8 minute blocks versus 1-2 hour lectures) and the use of podcasts as a feedback tool on key assessment tasks, which provided more timely feedback to students.

Providing prompt feedback is one of Chickering and Gamson's ${ }^{[21]}$ seven principles of good practice in undergraduate education. This principle was supported by external students who identified the podcast feedback as a valuable learning support, 'For other subjects I study externally the lectures have not had a big impact on me, but for this course the podcasts of lectures and podcasts of feedback on our assessments have made a huge difference to my understanding of topics' (CEI, 2009). In addition, one of the most important pedagogic supports offered by podcasting is 'learning through listening' especially for those students who do not like reading, 'As an external student ... podcasts of key concepts/lectures/feedback would have to be the strengths for me as I need to listen and hear the words' (CEI, 2008). Positive feedback from students led to the introduction of new vodcast technology that incorporated audio and screen capture casts into the main UniSA lecture theatres in 2010 and the introduction of picture-in-picture video, audio and screen capture casts in 2014.

\subsection{Videos}

In 2007, additional resources were introduced into the foundation course that included recording and uploading videos both of the practical dissections and of the use of various types of nursing equipment, as well as providing online simulated practical exercises. This was in response to feedback from external students who reported difficulties with their engagement in the practical aspect of this course. This is understandable, as students studying remotely have no opportunity to engage in 'face-to-face' laboratory work. Student feedback supported the idea that interactive videos are just as effective as print when it comes to learning and that video offers students the opportunity to gain insight into events they usually do not experience in real life. ${ }^{[22]}$

The video initiative was introduced to assist students who are visual and auditory learners and provide them with a semi-permanent resource that could be visited multiple times giving them the opportunity to develop a greater un- derstanding of the task. ${ }^{[23]}$ An external student's comment supports the success of the initiative, 'I found the practical DVD's dissections to be invaluable instructional tools, especially as an external student without any exposure to the practical tutorials' (CEI, 2007).

\subsection{Quizzes}

In conjunction with an education publishing company, a set of developmental formative online quizzes were created for each topic that could be taken progressively at any time and which provided instant feedback to students. ${ }^{[24]}$ This resource was used to help address the challenges faced by the $40 \%$ of all Bioscience students commencing their studies with limited background knowledge of the sciences.

The majority of students (93\%) enjoyed completing the online formative quizzes and found them interesting and helpful. As a result of regularly completing the quizzes at the completion of a topic, $85.5 \%$ felt their understanding of the course material increased. Students felt they learned more through the online formatives than lectures alone (59.8\%). The quizzes enhanced their understanding of the topic, complemented the lectures, provided useful feedback and were an effective revision tool.

\subsection{Case studies}

Online case study discussions were also developed and introduced to engage the affective domain, based on real world nursing concepts. These case studies acted as a scaffolded learning support to encourage self-directed learning and critical thinking. ${ }^{[25,26]}$ In this Inquiry Based Learning (IBL) approach, case studies relevant to the practical work being studied that week were posted on the external students' discussion forum and students were encouraged to post their responses. Staff then provided timely constructive feedback to keep students engaged in the process and allow solutions to the case studies to develop over the following week prior to beginning a new topic.

The success of the case study initiative is captured in the external students feedback in response to the CEI question: 'What were the best features of this course?', "The quality professional teaching and case study approach that were relevant to nursing" ... "The case studies allowed everyone to stay on track with study, encouraged good study habits and allowed us to review process" (CEI 2009). The IBL approach developed students' abilities to apply concepts, encouraged and promoted self-directed learning, collaboration and teamwork, and additionally prepared first year nursing students for group case presentation work, which is an integral component of compulsory second year Bioscience courses. ${ }^{[27]}$ This IBL approach using case studies to underpin nursing education is now used as a framework for undergraduate nursing curricula planning and evaluation. This initiative may also have contributed to the increase in the external student satisfaction from $78 \%$ in 2008 to $82 \%$ in 
2009, with respect to the CEI question, "Overall I was satisfied with this course". The introduction of the different initiatives and the affect they had on course satisfaction can be seen in Table 1.

\section{Initiatives (2012-2014)}

In 2012, it was still apparent that students lacking prior learning in the Biosciences were still struggling with subject content and in particular with complex processes and/or the application of concepts. These students were not engaging as fully with their learning as students with prior learning. Consequently in 2012, further initiatives were introduced to the bioscience course.

\subsection{Online learning and assessment tool}

In conjunction with Pearson publishing, an online learning and assessment tool was implemented for all 700 bioscience students to ameliorate the learning discord for students without prior learning in the Biosciences. By also using the online developmental quizzes introduced earlier in 2007 as a scaffold, Pearson's Mastering Anatomy and Physiology tool was modified to meet the needs of the bioscience students. Mastering A\&P is a powerful Socratic online tutorial, homework and assessment system, that provides students with engaging student-centred activities, interactive exercises and guided tutorial support. This online summa- tive assessment system was designed to help all bioscience students advance beyond simple memorisation of concepts to a genuine understanding of complex anatomy and physiology concepts. ${ }^{[28]}$ For example, students watch an animation on membrane transport with step-by-step explanations that show action and movement of molecules across membranes, thereby bringing difficult concepts to life. Students then need to answer questions on this concept. If they submit a correct answer they gain a bonus mark; an incorrect answer directs them to the relevant resource section of their textbook or the lecture notes/practical work.

An online survey (2012) of all students (internal and external) showed $76.5 \%$ agreed that the new learning tool increased their understanding of course material and $87.4 \%$ commented on its flexibility: "I could do them in a time I wanted which is good as I work full time". The integration of this type of learning technology, which combines both tutorial and summative assessment approaches, provided considerable scope for increasing the engagement of all students as evidenced by their free text responses in the survey: "Because they were due each week it forced me to stay on track and not get behind-this was very helpful for me as motivation is a HUGE problem studying externally". The Socratic approach provided instant feedback, which the students appreciated: "The instant feedback and hints on my wrong answers allowed me to know my strengths and weaknesses. It helped built up my confidence".

Table 1: Course Evaluation Instrument (CEI) data for Bioscience course 2006-2013

\begin{tabular}{lllllllll}
\hline & $\mathbf{2 0 0 6}$ & $\mathbf{2 0 0 7}^{*}$ & $\mathbf{2 0 0 8}$ & $\mathbf{2 0 0 9}^{\mathbf{\Lambda}}$ & $\mathbf{2 0 1 0}$ & $\mathbf{2 0 1 1}$ & $\mathbf{2 0 1 2}$ & $\mathbf{2 0 1 3}$ \\
\hline Overall I was satisfied with this course (\%) & 48 & 78 & 78 & 82 & 86 & 88 & 88 & 94 \\
Number in class & 100 & 120 & 80 & 133 & 252 & 276 & 258 & 181 \\
Response rate (\%) & 33 & 60 & 69 & 51 & 35 & 30 & 33 & 44 \\
\hline
\end{tabular}

* the introduction of Podcasts, videos and developmental online quiz initiatives;

$\Delta$ the introduction of IBL case study initiative;

- the introduction of online Socratic assessment, virtual classrooms and peer support initiatives.

Students said they enjoyed the hints and other learning objects such as animations, images and videos that have been embedded in this program to assist them in their learning: "I am a visual learner so I found the pictorial questions assisted my learning and I could really engage in this subject".

\subsection{Virtual classroom}

External Bioscience students do not have the opportunity to engage in real-time practical aspects of the course. For many years the external students have performed poorly in the practical exam compared to internal students, who attend practical classes on campus. In past years (2009-2011 inclusive), the external students practical exam pass rates were $54.5 \%$ lower than those of the internal cohorts, worth $35 \%$ of their final grade. The Virtual Classroom (VC) was introduced in 2012 to engage external students more deeply in the practical component of the course. Several virtual classrooms were made available to external students at multiple times and days each week. Students could then choose on a weekly basis a timeslot that suited them. Adobe Connect software was used, which mimics the face-to-face classroom in many ways with a roster, hand-raising icon and an instructor leading the group. The major benefits of using a virtual classroom are: providing immediate feedback, encouraging the exchange of multiple perspectives, enhancing dynamic interactions among participants, strengthening social presence, fostering the exchange of emotional supports and supplying verbal elements. ${ }^{[29-31]}$

An online survey of external students was conducted at the end of 2012, which suggests that the new virtual classroom has created valuable learning opportunities particularly through the immediacy of the technology in promoting 
student/student and student/lecturer interaction. The virtual classrooms have helped foster mutual collaboration between students, enhanced their sense of online community and reduced anxieties, as evidenced by student comments: "VC allowed us externals to become part of a group"... "It felt like I was part of the course and not alone". The survey showed that $92 \%$ believed engagement in the virtual classroom increased their understanding of course work and $86 \%$ believed it better prepared them for both their practical and final exams. "... I genuinely feel that the VC has better prepared me for my exams compared to my other subjects I study". The virtual classroom also supported the external students' mode of study: "It gave me the flexibility to remain external with the internal benefits".

\subsection{Peer mentoring}

The university's Student Coaching Scheme (SCS) was designed initially in 2004 to assist only internal students in the bachelor degree in nursing. ${ }^{[32]}$ In 2012, with the introduction of virtual classrooms, a new scheme (Virtual Buddies) was set up to support 'at risk' external students. The aims of the scheme were to:

(1) recognise and reward successful nursing students in the same year level

(2) provide individual and group coaching for students with little or no science background

(3) support nursing students who have been identified as at risk

(4) reduce the workload of the course academic staff

Students 'at risk' were identified from their poor performance in a number of early summative assessment pieces conducted in weeks two through five. Bioscience students who gained perfect or near perfect in these assessments were identified and invited to become Virtual Buddy Leaders. Training was provided to those who accepted by the teaching staff and the Virtual Buddy Leaders worked closely with them throughout the study period. Staff organised session times and supplied broad academic discussion topics for each week. The virtual sessions were recorded and made available so students could access them at their own time/pace. The focus of the sessions was on study strategies and the forthcoming assessments for the course. All participants were asked to complete evaluations on their experiences of the sessions.

The majority (98\%) of external Bioscience students' affirmed that the aims of the virtual classrooms run by Virtual Buddies were fulfilled. A current, 2013 at risk student commented, "I felt supported at a time when I just wanted to withdraw". The Virtual Buddies themselves are also enthusiastic about the program as well as the opportunity to help fellow students and improve their own skills. A positive response from a VB included, "Personally I did get a lot out of tutoring in the virtual classroom as it not only gave me satis- faction to be able to help other students learn, but it provided me an opportunity to revise myself'. Although not all comments were as positive: "I feel rushed to get through the topics in the detail they need to understand the concepts of the course. I feel that we need to spend one week on each topic so they can understand it better." Overall, we found that peer mentoring in higher education is an effective intervention to assist with the success and retention of vulnerable students and that a successful peer system must be one that is specifically designed with peer tutors in mind. ${ }^{[33-35]}$ The culmination of all these initiatives has created a new e-environment that has contributed to improved student learning. In 2012, the externals practical exam pass rate was $35.41 \%$ higher than the internals; there were fewer non attendances at the external practical exam (now $4 \%$ compared to $>12 \%$ previously) and the external students' final grades now peak in the Distinction range (see Figure 1). In 2013 external student grades were of a similar trend to that of 2012 .

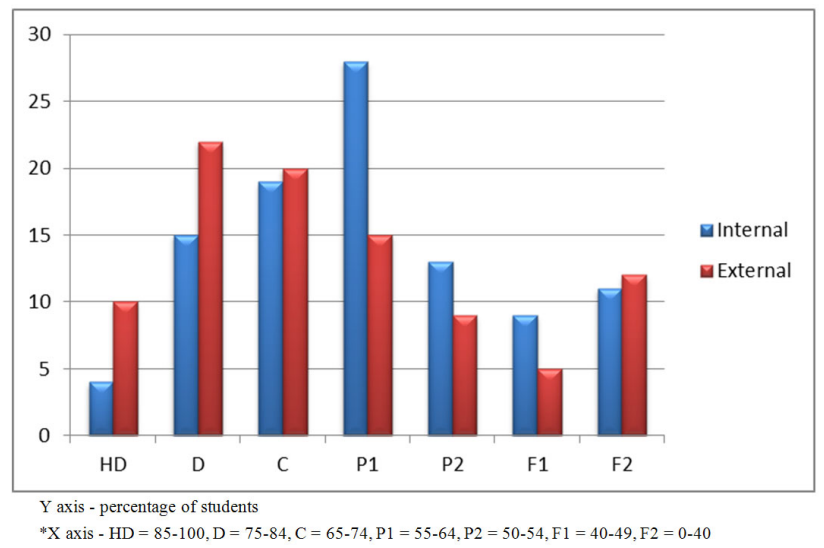

Figure 1: The numbers indicate the different percentages of student final grades* for the bioscience course, SP2, 2012 noting the difference between internal and external cohorts (258 external students; 452 internal students)

\section{Discussion}

The modification and introduction of new initiatives introduced into an existing didactic face-to-face course in order to support the unique needs of the external learner has occurred over several years and has provided staff and students with challenges as well as rewards. These new initiatives have all contributed to a more positive, supportive online learning environment for the external Bioscience student that has alleviated much of the anxiety and isolation that distance learners experience when studying remotely in an electronic environment. ${ }^{[30,31,36,37]}$ This is reflected in a CEI (2007-2008) response, "The best features of this course was the way it was set out for an external student... DVD's, vodcasts, the discussion forum, case studies, superb feedback and the fantastic lecturer were all above what I have 
experienced at Uni”. Feedback and assessment are important drivers of student performance and gauge of student progress, as well as an effective means of objectively examining the effectiveness of teaching. We found that the interactive and dialogic dimension of feedback requires careful planning in the same way as preparing the delivery of content. [38]

In most science-based subjects assessment is typically summative in nature and tends to encourage surface or rote learning, which provides immediate benefit for short term exams but does little for life time learning. This type of feedback on learning is especially valuable in the nursing program where our future professionals need to rely less on memorising material and more on understanding concepts and processes to build their knowledge and support their practice. We found that the integrated use of both formative and summative assessment, such as the introduction of the Socratic assessments in Bioscience courses, provides an inquisitive and active approach to facilitate student learning. [39]

A further problem with traditional summative assessments of student learning is that they are often conducted at the end of course work. By assessing Bioscience students weekly throughout the course, this enables staff to provide them with instant feedback on where they are going wrong (and right!) and coaching to help them with conceptual understanding. These assessments better prepared all Bioscience students for their weekly practical tutorials, improved their engagement and facilitated deeper learning. ${ }^{[28,40]}$ Given that marks are a strong motivating factor for students to undertake assessments, an aggregate of $15 \%$ of the final grade was allocated for weekly summative submissions. The formative online quizzes developed in 2007 were also used to supplement other learning methods such as lectures and practicals, and were used by students for revision purposes. The outcomes seen for Bioscience students are consistent with those reported for other courses that have incorporated continuous assessment even though the actual assessment methods and pedagogical structures differ considerably. ${ }^{[28]}$ These results illustrate the relevance of a scaffolded approach to learning, where topics are structured to culminate in a summative weekly assessment. It also succeeds as a method of formative assessment that provides feedback on performance to accelerate and improve student learning. Beebe et al. ${ }^{[41]}$ confirms that assessment leading to continuous improvement is important for the development and engagement of learners in an online environment.

The virtual classroom allows educators to blend both traditional and virtual learning environments with special attention to external students' needs e.g. it provides the opportunity to give highly individualised responses to students as well as timely support to the distance learner before key assessments. ${ }^{[24,41]}$ This is a strategic point for support because students are anxious, highly motivated and most open to guidance.

Peer mentoring in higher education is an effective intervention to assist with the success and retention of vulnerable students and that a successful peer system must be one that is specifically designed with peer tutors in mind. ${ }^{[33-35]}$ The peer mentoring scheme initiative provided 'at risk' students with not only another chance for deeper learning but as an avenue of synchronous online learning that decreased their sense of isolation by adding to their sense of online community. ${ }^{[29]}$ Our results show that the advantage of initiating a mentoring scheme within the same year level group helps both Virtual Buddy Leaders and the Buddies as they progress through the program together. This enables students to develop networking, friendships, cross-cultural experiences and a close rapport with their peers, stimulating a relationship based on equality. This suggests that improved pass rates in first year may persist, further strengthening retention in later years. Such advantages are lost in a hierarchical model of mentoring as senior mentors graduate. ${ }^{[33,42]}$ The Student Coaching Scheme offers additional benefits in enhancing recognition for students who excel in sciencebased courses and facilitates the sharing of knowledge and experiences. The scheme reduces the levels of anxiety experienced by students who struggle to engage with course material or with the university in general.

The introduction of key initiatives also correlates well with an overall increase in external student satisfaction with the course with respect to the CEI question; Overall I was satisfied with this course (see Table 1). Students who report having a positive first year experience are more likely to remain in the program. ${ }^{[18,19,43]}$

\section{Conclusion}

The Tertiary Education Qualification Standards Agency (TEQSA, 2013), have found that external students may not be receiving an equivalent education to their face-to-face counterparts. This paper provides evidence to support how a number of initiatives that were developed and introduced into a traditional on campus and an off campus bioscience course over a number of years have provided a supportive learning environment to support external nursing students.

Main findings show that the new initiatives provided external nursing students with the opportunity to overcome their anxieties, increase their sense of online community and promote social networks that may persist, further strengthening retention in later years, facilitate a higher level of in-depth understanding of complex concepts, contribute to higher retention and overall student satisfaction.

This paper has shown that developing and implementing flexible, supportive online resources and encouraging selfdirected learning in students has taken considerable time and thought. In our experience, creating a successful on- 
line learning environment for external students has not decreased time spent teaching, nor decreased costs or made teaching easier. However, it has led to improved student retention and the quality of the learning experience for external students in our bioscience courses.

\section{References}

[1] Australian Bureau of Statistics. Australian Bureau of Statistics year book 2009-2010.

[2] Coates, H. Student engagement in campus-based and online education: University Connections, London: Routledge; 2006.

[3] Barkley, E. F. Student engagement techniques: A handbook for college faculty, San Francisco: Jossey-Bass; 2010.

[4] Bryson, C. and Hand, L. The role of engagement in inspiring teaching and learning, Innovations in Education and Teaching International. 2007; 44(4): 349-362. http://dx.doi.org/10.1080/1 4703290701602748

[5] Hockings, C. Cooke, S., Yamashita, H., McGinty, S., and Bowl, M. Switched off? A study of disengagement among computing students at two universities, Research Papers in Education. 2008; 23(2): 191201. http://dx.doi.org/10.1080/02671520802048729

[6] Curry, M. and Smith, L. Twelve tips for authoring on-line distance learning medical post-registration programmes, Medical Teacher. 2005; 27(4): 316-321. PMID:16024413 http://dx.doi.org/1 $0.1080 / 01421590500087175$

[7] Clark, R and Mayer, R. E. E-Learning and the Science of Instruction, Wiley and Sons; 2011. http://dx.doi.org/10.1002/978 1118255971

[8] Garrison, D. R. E-Learning in the 21st Century: A framework for Research and Practice, New York: Routledge; 2011.

[9] Horton, W. e-Learning by Design, John Wiley and Sons; 2011.

[10] Bogle, L. Day, S. Matthews, D. \& Swan, K. The power of a collaborative, collegial approach to improving online teaching and learning. In K Shattuck (Ed.) Assuring quality in online education: Practices and Processes at Teaching, Resource, and Program Levels; Stylus Publishing; 2014; 110-123.

[11] Palloff, R. and Pratt, K. Building Online Learning Communities: Effective strategies for the virtual classroom, San Francisco: John Wiley and Sons; 2007.

[12] Wu, J., Tennyson, R. D., Hsia, T. A study of student satisfaction in a blended e-learning system environment, Computers and Education. 2010; 55(1): 155-164. http://dx.doi.org/10.1016/j.compe $\mathrm{du} .2009 .12 .012$

[13] Douglas J, Davies, J \& McClelland, R. The development of a conceptual model of student satisfaction with their experience in higher education. Quality insurance in education. 2007; 16(1): 19-35. http://dx.doi.org/10.1108/09684880810848396

[14] Frankola, K. (2001). Why online learners drop out. Workforce. 2001; 80(10): 53-59. Available from: http://www.workforce. com/articles/why-online-learners-drop-out

[15] Diaz, D. Online drop rates revisited. Retrieved August 11, 2005, University of North Carolina, The Technology Source Archives Website. 2002. Available from: http://technologysource.org /article/online_drop_rates_revisited/

[16] Health Workforce 2025 study. Health Workforce Australia. 2012. Available from: https://www.hwa.gov.au/health-workforce-2025.

[17] Gaskell, A. Student Satisfaction and retention: are they connected? Open Learning: The Journal of Open, Distance and e-learning. 2009.

[18] Peterson, M., Wagner, J. A. and Lamb, C. W. The Role of Advising in Non-Returning Students' Perceptions of Their University, Journal of Marketing for Higher Education. 2001; 10(3): 45-59. http://dx.doi.org/10.1300/J050v10n03_03

[19] Schertzer., C. \& Schertzer, S. Student Satisfaction and Retention: A Conceptual Model, Journal of Marketing for Higher Education.
2004; 14(1): 79-91. http://dx.doi.org/10.1300/J050v14n0 $1 \_05$

[20] Cebeci, Z. and Tekdal, M. Using Podcasts as Audio Learning Objects. Interdisciplinary Journal of Knowledge and Learning Objects. 2006; 2: 47-57.

[21] Chickering, A. W. and Gamson, Z. F. Seven Principles for Good Practice in Undergraduate Education, AAHE Bulletin. 1987; 39(7): 3-7. Available from: http://www. aahea.org/aahea/articles /sevenprinciples $1987 . \mathrm{html}$

[22] Merkt, M., Weigand, S., Heier, A. and Schwan, S. Learning with videos vs. learning with print: The role of interactive features, Learning and Instruction. 2011; 21: 687-704.

[23] McConville, S. A. and Lane, A. M. Using on-line video clips to enhance self-efficacy toward dealing with difficult situations among nursing students, Nurse Education Today. 2006; 26: 200208. PMID:16300862 http://dx.doi.org/10.1016/j.nedt. 2005.09.024

[24] All, A. C. A behind the scenes look at the Faculty Role in the Online Learning Environment. In Brosche, T. \& Feavel, M. (Eds) Successful Online Learning: Managing the Online Learning Environment Efficiently and Effectively. Jones and Bartlett Publishers; 2011; 159170.

[25] Prince, M. and Felder, R. The many faces of inductive teaching and learning, Journal of College Science Teaching. 2007; 36(5): 14-20.

[26] Levy, P., S. Little, P. Mckinney, A. Nibbs, and J. Wood. The Sheffield companion to inquiry-based learning. Brook Hill, UK: Centre for Inquiry-based Learning in the Arts and Social Sciences (CILASS), The University of Sheffield. 2010. Available from: http://www.academia.edu/558457/The_Sheffield_ Companion_to_Inquiry-Based_Learning

[27] Mason, R. and Rennie, F. E-learning: The Key Concepts. London: Routledge Press; 2006.

[28] Rushton, A. Formative assessment: a key to deep learning. Medical teacher. 2005; 27(6): 509-513. PMID:16199357 http://dx.doi .org/10.1080/01421590500129159

[29] Park, Y. J. and Bonk, C. J. Is life a Breeze? A case study for promoting synchronous learning in a blended graduate course, Journal of Online Learning and Teaching. 2007; 3(3): 307-323.

[30] Moore, M. Theory of Transactional Distance. In D. Keegan (Ed.) Theoretical Principles of Distance Education. Routledge. 1997; 2238.

[31] McInnerney, J., and Roberts, T. Online Learning: Social Interaction and the Creation of a Sense of Community, Educational Technology and Society. 2004; 7(3): 73-81

[32] Thalluri, J., Kokkinn, B., and O'Flaherty, J. A Student Coaching Scheme for First Year University Students: Positive Learning Experience and Individual Successes in Biosciences. The International Journal of Learning. 2008; 15(9): 135-144.

[33] Colvin, J. W. Peer tutoring and social dynamics in higher education. Mentoring and Tutoring: Partnership in Learning. 2007; 15(2): 165-181. http://dx.doi.org/10.1080/13611260601086345

[34] Dixon, J., Crooks, H., Henry, K. Breaking the ice: Supporting collaboration and the development of community online. Canadian Journal of Learning and Technology. 2007; 32(2). Available from: http://www.cjlt.ca/index.php/cjlt/article/vie $\mathrm{w} / 51 / 48$

[35] Terrion, J. L. and Leonard, D. A taxonomy of the characteristics of student peer mentors in higher education: findings from a literature review, Mentoring and Tutoring. 2007; 15(2): 149-164. http://dx.doi.org/10.1080/13611260601086311 
[36] Abbot-Chapman, J., Hughes, P., and Wyld, C. Monitoring student progress: a framework for improving student performance and reducing attrition in higher education, Hobart: National Clearinghouse Press Ltd for Youth Studies of Tasmania and Hobart; 1992.

[37] Palloff, R. and Pratt, K. Building Virtual Communities: Techniques that work! 23rd Annual Conference on Distance Teaching and Learning. 2007.

[38] Molloy, E. Time to Pause: giving and receiving feedback in Clinical Education, Clinical Education in the Health Professions. Elsevier Australia; 2009; 128-146.

[39] Peterson, E. Teaching to think: Applying the Socratic Method outside the Law School Setting, Journal of College Teaching and Learning. 2009; 6(5): 83-88.
[40] Biggs, J. and Tang, C. Teaching for Quality Learning at University, 4th Ed., SRHE and Open University Press, McGraw Hill; 2011.

[41] Beebe, R., Vonderwell, S., and Boboc, M. Emerging patterns in transferring assessment practices from face-to-face to online environments, Electronic Journal of E-Learning. 2010; 8(1): 1-12.

[42] Lopez, C. L. A decade of assessing student learning: what we have learned; what's next? Chicago: North Central Association of Colleges and Schools Commission on Institutions of Higher Education. 1999.

[43] Kift, S. Articulating a transition pedagogy to scaffold and to enhance the first year student learning experience in Australian higher education, Final report for ALTC Senior Fellowship Program. 2009. 